\title{
Significant changes in subseries means and variances in an 8000-year precipitation reconstruction from tree rings in the southwestern USA
}

\author{
Jianmin Jiang ${ }^{1,2,3}$, Xiangqian $\mathbf{G u}^{4}$, and Jianhua $\mathbf{J u}^{1}$ \\ ${ }^{1}$ Training Center of China Meteorological Administration, Beijing, 100081, China \\ ${ }^{2}$ Joint Institute of Marine and Atmospheric Research (JIMAR), University of Hawaii, Honolulu, HI, 96822, USA \\ ${ }^{3}$ Pacific Fisheries Environmental Laboratory, NOAA/NMFS, Pacific Grove, CA, 93950, USA \\ ${ }^{4}$ Chinese Academy of Meteorological Sciences, Beijing, 100081, China
}

Received: 2 October 2006 - Revised: 4 June 2007 - Accepted: 27 June 2007 - Published: 30 July 2007

\begin{abstract}
Both algorithms were applied to an 8000-year long time series of annual precipitation that was reconstructed from tree rings in the southwestern USA. One of the algorithms is the scanning $t$-test, which detects significant changes in subseries means (the first center moments) on various time scales. Another is the scanning $F$-test, which detects significant changes in subseries variances (the second center moments) on multi-time scales. Firstly, the scanning $t$-test identified 22 change points in subseries means and partitioned the series into 23 relatively wet, normal or dry episodes. Secondly, the scanning $F$-test detected 15 change points in subseries variances and divided 16 phases in comparatively steady (with smaller variance) or unsteady (with larger variance) features. Thirdly, the 23 wetness-episodes were characterized as the steady or unsteady situations by jointing the results from the scanning $F$-test into those from the $t$-test. Fourthly, the 23 episodes were compared to those in the TIC and $\delta^{18} \mathrm{O}$ records from cored sediments in the deep basin of the Pyramid Lake in Nevada by using a coherency analysis of the $t$-test between the precipitation reconstruction and the TIC or $\delta^{18} \mathrm{O}$ series. Fifthly, the 23 episodes were collaborated with some published papers in related studies. In addition, the 23 episodes were also compared with studies of the global climate change and with documents of climate changes in China during the same periods. As the TIC and $\delta^{18} \mathrm{O}$ record series are high resolution with unequal sampling intervals between 3 and 14 years, an algorithm in the scanning $t$-test for dealing with the unequal time intervals was developed in this study.
\end{abstract}

Keywords. Geomagnetism and paleomagnetism (Time variations, secular and long term) - Meteorology and atmospheric dynamics (Precipitation) - General or miscellaneous (Techniques applicable in three or more fields)

Correspondence to: Jianmin Jiang

(jiangjm93950@yahoo.com)

\section{Introduction}

Hughes and Graumlich (1996) reported a valuable dendroclimatic study of annual (prior July through current June) precipitation reconstruction for the period from $6000 \mathrm{BC}$ to $1996 \mathrm{AD}$ for the climate division 3 in south-central Nevada, based on the Methuselah Walk tree ring chronology from the White Mountains in California, in southwestern USA (Fig. 1). They emphasized the striking pattern of two multidecadal droughts in the epoch between $900 \mathrm{AD}$ and $1400 \mathrm{AD}$ and listed eight extreme drought years, in which bidecadally filtered values of the precipitation reconstruction were below $17 \mathrm{~cm}$. However, no analysis of statistically significant changes was reported for this series before.

Karl and Riebsame (1984) detected fluctuations in air temperature and precipitation in the USA with the Student $t$-test. Yamamoto et al. (1986) modified the $t$-test into a ratio of signal-to-noise as criterion to analyze "climatic jump". Goossen and Berger (1987) defined an abrupt climate change or a climatic discontinuity as an abrupt and permanent change during the period of record from one average value to another, and employed the Mann-Kendall rank test to recognize the abrupt climatic change. However, they discuss only about the subsample average and search only one change point per calculation in a time series. The IPCC (2001) has a consensus that the climate change includes two contents: changes of subseries means (the first center moments) and changes of subseries variances (the second center moments). Jiang et al. (2001, 2002, 2003) grafted the wavelet technique (Kumar and Foufoula-Georgiou, 1994) onto the Student $t$-test and the $F$-test (Cramer, 1946) to develop algorithms of scanning $t$-test and scanning $F$-test, respectively. The scanning $t$ test detects significant changes in the first moments (subseries means or averages) at each time period on various time scales in a long time series, while the scanning $F$-test detects significant changes in subseries variance (the second moments) at each time period on various time scales

Published by Copernicus Publications on behalf of the European Geosciences Union. 


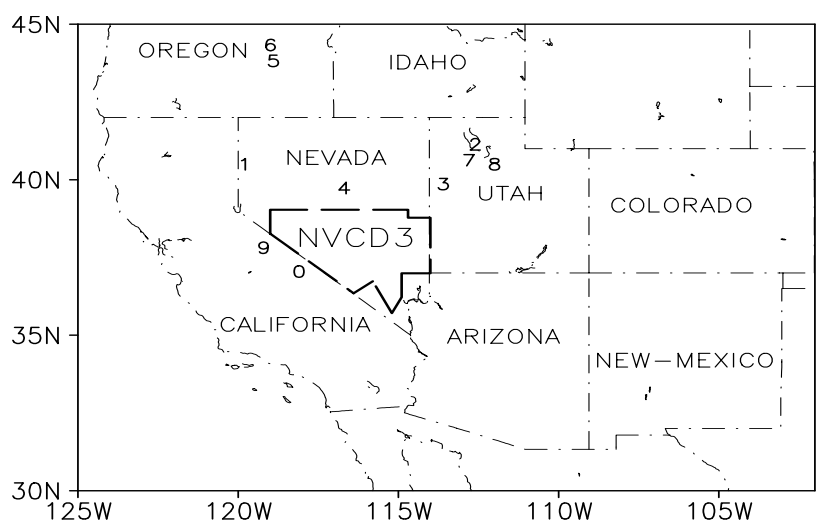

Fig. 1. Locations of the Nevada Climate Division 3 (NVCD3) and 10 numbered sites that are mentioned in Sects. 1 and 6. (The numbers indicate: 0 - White Mountains, 1 - Pyramid Lake, 2 - Great Salt Lake, 3 - Danger Cave, 4 - Potato Canyon Bog, 5 - Diamond Pond, 6 - Malheur Maar, 7 - Homestead Cave, 8 - Snowbird Bog, 9 - Mono Lake).

in a long time series. The algorithms give thresholds at a given statistical confidence, as well as detect multiple significant change points on multi-time scales. In order to avoid the argument of how to separate exactly "abrupt change" from "gradual change", we use "significant change" in both the average and variance instead of "abrupt change" in the average. This may agree more exactly with the statistics. A significant change means that the difference in the subseries statistics between the two adjoining subseries is statistically significant at a given statistical confidence in that statistical test. The statistics include the average or mean (the first moment) and the variance or standard deviation (the second moment) in this study.

This paper attempts to apply both algorithms of the scanning $t$-test (Jiang et al. 2001, 2002) and the scanning $F$-test (Jiang et al., 2003) to the unfiltered precipitation reconstruction for the Nevada climate division 3; here the unfiltered precipitation reconstruction represents that has not been filtered bidecadally (Hughes and Graumlich, 1996). Firstly, the scanning $t$-test identifies twenty-two change points, and 23 comparatively climatic wetness-episodes are partitioned in the 8000-year precipitation reconstruction series. Secondly, the scanning $F$-test detects 15 change points in subseries variance and divides 16 phases in comparatively steady (with smaller variance) or unsteady (with larger variance) features. Thus, the 23 wetness episodes are characterized as the steady or unsteady traits by joining the results from the scanning $F$-test into those from the $t$-test. Thirdly, to verify the significant changes in subseries averages in the unfiltered precipitation reconstruction series, we employ the coherency detection algorithm based on the scanning $t$-test (Jiang et al., 2002) to the precipitation reconstruction and other two high-resolution time series, the TIC (Total Inor- ganic Carbon fraction) and $\delta^{18} \mathrm{O}$ records from cored sediments in the deep basin of the Pyramid Lake (see Fig. 1) in Nevada (Benson et al., 2002). The coherency detection algorithm tests synchronously and asynchronously significant changes in the subseries levels between the two time series on multi-time scales. Thirteen change points appear in the precipitation reconstruction which are close to those in the TIC or $\delta^{18} \mathrm{O}$ series within 150 years of difference and covering the overlapping years by more than $2 / 3$ of the episode duration. Finally, we confirm the 23 wetness-episodes with previously published research into the climatic change periods in the western USA, and find that 22 of the 23 episodes coincide with the previously published results. In addition, the 23 episodes are also compared with studies of climate changes in the eastern China, as well as of global changes. As known, eastern China and western USA are located on the western and eastern coasts of the Northern Pacific, respectively, and China is located in the upstream, while the USA are located in the down-stream of the westerlies in the general atmospheric circulation. They are all influenced by the ENSO, and PDO and other factors but with different after effects.

The motives of this study are to examine the practicality of the algorithms, the reliability of the precipitation reconstruction data and to discuss the possible associations of climate changes in the western USA with the global changes and climate changes in China during the last 8000 years.

\section{Methodology}

\subsection{Two contents of climate change}

Figure 2 illustrates two aspects of climate change, which were proposed in the IPCC (2001). Suppose a meteorological element in the normal distribution, when the subseries means (the first moments) move to higher value, the probability of extreme high events (climate disasters) increases, while the probability of extreme low events (opposite climate disasters) decreases, otherwise vice versa (upper panel). On the other hand, when the subseries variances (the second moments) become larger, the probabilities of both sides of the extreme events (climate disasters) increases, and otherwise vice versa (lower panel). In this study, we attempt to introduce and apply algorithms for detecting both aspects of significant climate changes.

\subsection{The scanning $t$-test and coherency detection}

In the scanning $t$-test, the statistic $t(n, j)$ is defined to measure differences of subsample averages between every two adjoining subseries with equal subsample size $(n)$ as follows (Jiang et al., 2002):

$t(n, j)=\left(\bar{x}_{j 2}-\bar{x}_{j 1}\right) \cdot n^{1 / 2} \cdot\left(s_{j 2}^{2}+s_{j 1}^{2}\right)^{-1 / 2}$, 
where

$\bar{x}_{j 1}=\frac{1}{n} \sum_{i=j-n}^{j-1} x(i), \quad \bar{x}_{j 2}=\frac{1}{n} \sum_{i=j}^{j+n-1} x(i) ;$

$s_{j 1}^{2}=\frac{1}{n-1} \sum_{i=j-n}^{j-1}\left(x(i)-\bar{x}_{j 1}\right)^{2}$;

$s_{j 2}^{2}=\frac{1}{n-1} \sum_{i=j}^{j+n-1}\left(x(i)-\bar{x}_{j 2}\right)^{2}$,

where the subsample size $n$ may vary as $n=2,3, \ldots,<N / 2$, or may be selected at suitable intervals. The $j=n+1, n+2, \ldots$, $N-n+1$ is the reference time point, at which a significant change point is to be tested on the time scale $n$ in the timeseries with total records $N$.

For those series with unequal sampling intervals, we let $j$ denote the order of records in time sequence, while $Y(j)$ indicates the corresponding year at the $j$-th record in the chronology. The sample number is taken as $\{(j-1)-(j-n)\}$ and $\{(j+n-1)-j\}$, respectively, while the time scale (subseries duration) is controlled by letting $\{Y(j-1)-Y(j-n)\}$ or $\{Y(j+n-1)$ $Y(j)\}$ equal to or less than the given scale. In this work, the sample size (number) $n$ is less than the time scale.

Since the series examined in this paper are somewhat autocorrelated, for example, in the precipitation reconstruction the lag-1 autocorrelation coefficients vary between -0.29 and +0.26 in pooled subsamples of length $2 n$. The TableLook-Up Test (Von Storch and Zwiers, 1999) is adopted to correct the significance criterion of the statistic $t(n, j)$ according to the lag-1 autocoefficients of the pooled subsample and the subsample size $n$. Criterion $t_{005}$ for the correction of the dependence is usually selected to determine significant changes on time scales longer than 30 years. For shorter subsample sizes, the critical values are usually overly restrictive.

Since the significance level varies with $n$ and $j$, to make values comparable, the test statistic is normalized as:

$t_{r}(n, j)=t(n, j) / t_{0.05}$,

so that a significant change is at the $95 \%$ confidence level when $\left|t_{r}(n, j)\right|>1.0$, with $t_{r}(n, j)<-1.0$ denoting a significant decrease, and $t_{r}(n, j)>1.0$ indicating a significant increase in the time series.

Finally, a coherency index of significant changes between the two series $u$ and $v$ is defined as the statistic $t_{r c}(n, j)$ :

$t_{r c}(n, j)=\operatorname{sign}\left[t_{r u}(n, j) \cdot t_{r v}(n, j)\right]\left\{\left|t_{r u}(n, j) \cdot t_{r v}(n, j)\right|\right\}^{1 / 2}$

Usually, a center (local maximum) of $t_{r c}(n, j)>1.0$ with both $\left|t_{r u}(n, j)\right|$ and $\left|t_{r v}(n, j)\right|>1.0$ represents a pair of significant changes in the same direction (in-phase), while the center (local minimum) of $t_{r c}(n, j)<-1.0$ denotes a pair of significant changes in the opposite direction (anti-phased).

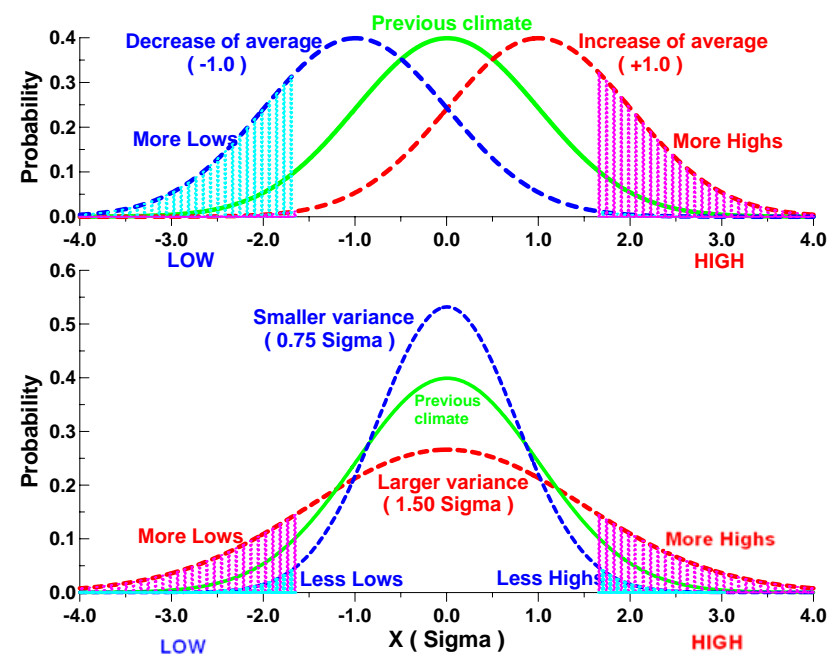

Fig. 2. Illustration of two contents in climate changes.

\subsection{The scanning $F$-test}

Similarly, in order to detect significant changes in subseries variances (the second centre moments), the index $F_{r}(n, j)$ of the scanning $F$-test is defined as:

$F_{r}(n, j)=\left\{\begin{array}{c}-\left(S_{j 1}^{2} / S_{j 2}^{2}\right) / F_{\alpha}, \text { for } S_{j 2}<S_{j 1}, \\ 0, \text { for } S_{j 2}=S_{j 1} \text { or } S_{j 1}=0, S_{j 2}=0 \\ \left(S_{j 2}^{2} / S_{j 1}^{2}\right) / F_{\alpha}, \text { for } S_{j 2}>S_{j 1}\end{array}\right.$,

where the subsample standard deviations $S_{j 1}$ and $S_{j 2}$ are calculated in the same way as in (1), and similarly $n=2,3, \ldots$, $<N / 2, j=n+1, n+2, \ldots, N-1 . F_{\alpha}$ is a threshold value on the effective degree of freedom after the correction of dependence and in a normalized distribution for the time series. A local minimum in $F_{r}(n, j)<-1.0$ denotes a significant change towards a smaller variance, i.e. the records become much steadier, whereas a local maximum in $F_{r}(n, j)>1.0$ indicates a significant change towards a larger variance, i.e. the records become much unsteadier. In this algorithm, the subseries variance measures deviations from the subseries mean.

The estimation of the effective degree of freedom for the correction of the dependence is taken as (Hammersley, 1946):

$E f(n)=f(n) \cdot\left[\sum_{\tau=0}^{k} r^{2}(\tau)\right]^{-1}, r(k) \rightarrow 0$

where $f(n)$ is the degree of freedom listed in the $F$ form.

\section{Data sources}

Three time series: the unfiltered precipitation reconstruction, the TIC and $\delta^{18} \mathrm{O}$ records are used in this work. The unfiltered precipitation reconstruction series was downloaded from the website http://www.ngdc.noaa.gov/paleo/drought/ 

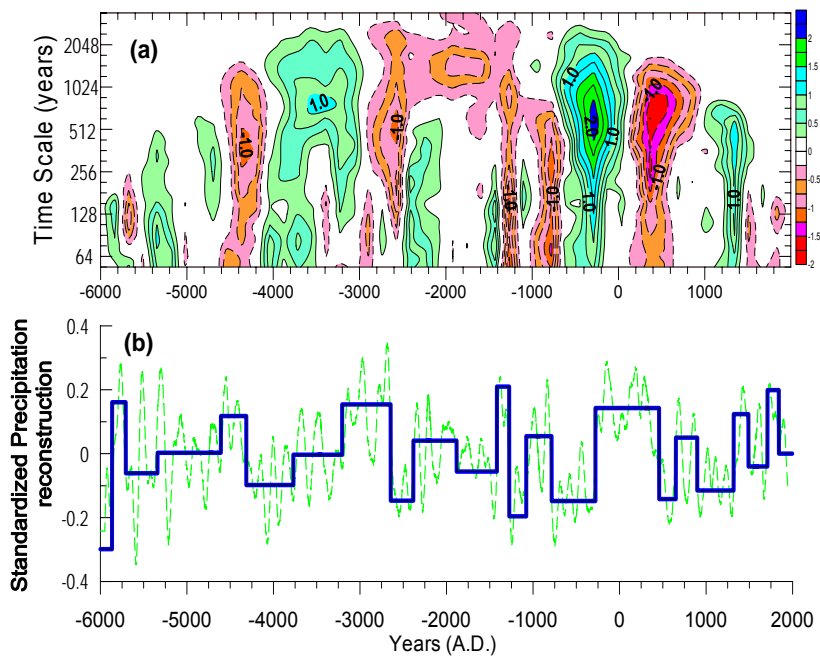

Fig. 3. (a) Contours of the normalized scanning $t$-test for the precipitation reconstruction series at confidence level 95\%. Contour interval is 0.25 but the zero-contour is hidden. Solid lines denote positive values, dashed lines negative values. (b) Change points and episode averages (solid line) from panel (a), 101-year Gaussian filtering of the precipitation reconstruction (dashed line), the average over the entire time series is zero after standardization.

(Hughes and Graumlich, 2000). The series contains a reconstructed annual (prior July-current June) precipitation (in cm) for the Nevada Climate Division 3 (see the NVCD3 in Fig. 1), including a total of 7997 years from $6000 \mathrm{BC}$ to $1996 \mathrm{AD}$ (referred to as the precipitation reconstruction hereafter). It was reconstructed by using the whitened Methuselah Walk tree ring chronology from the White Mountains of California; the location is shown as number " 0 " in Fig. 1. Other numbered sites in Fig. 1 will be mentioned below and in Sect. 6. This tree ring chronology is the longest absolutely dated in a single species of the bristlecone pine, at almost 9000 years long. It is made up of 285 tree ring samples with a mean length of 748 years, of which about 14 series are present in each year for the whole period after $6000 \mathrm{BC}$. These tree ring samples were collected by the Laboratory of tree ring Research, University of Arizona. In order to remove any growth trend of the trees, they standardized all tree ring samples with either negative exponential or a straight line with a zero or negative slope. The Box-Jenkins model was fitted (ARMA 1, 1), which accounted for only $5.74 \%$ of the series variance, and the series was whitened by computing the residuals from this model. The whitened Methuselah Walk chronology was calibrated in regression to annual precipitation observations in the Nevada Climate Division 3 during the period from 1932 to 1979 , and then extrapolated to other years. This regression fitted 35\% variance of the precipitation observations. Both power spectrum and singular spectrum analyses indicate that very little of the variance of this chronology can be represented by trend, or by periodic or quasi-period compo- nents. More details about the data are described in Hughes and Graumlich (1996).

The TIC and $\delta^{18} \mathrm{O}$ high-resolution records from cored sediments in the deep basin of the Pyramid Lake (see number "1" in Fig. 1) in Nevada were kindly provided by L. Benson at USGS. These data sets were sampled from 2 piston cores of sediments in the center Pyramid Lake in 1997 (referred as PLC97-1) and in 1998 (PLC98-4), separately. The sites of the 2 cores are very close to each other. The PLC97-1 covers the period from $793 \mathrm{BC}$ to $1839 \mathrm{AD}$ and 533 records were read at unequal intervals between 3 and 9 years. Its age control was established by comparing its palemagnetic secular variation (PSV) record with a well-dated western USA archeomagnetic record (Lund, 1996), and the age model accurance was considered within 50-100 yr. The PLC98-4 was taken to recover older Holocence-age sediments, which covers the period from $5680 \mathrm{BC}$ to $1480 \mathrm{BC}$, and 538 records were read in unequal intervals between 4 and 14 years. Radiocarbon ages were determined on the TOC (Total Organic Carbon fraction) of this core and probably remained as larger errors. Further descriptions of the TIC and $\delta^{18} \mathrm{O}$ data sets can be found in Benson et al. (2002).

\section{Significant changes in precipitation reconstruction se- ries}

\subsection{Results from the scanning $t$-test}

The scanning $t$-test was computed for time scales (subsample sizes) ranging from 54 to 2896 years following equation (1) and (2) at a 95\% confidence level. We calculate the time scales up to 2896 years in consideration mainly of two reasons: one is the mathematical capability, and the other reason is that more than 10 tree ring series cover the whole period after 6000 BC. Based on the local maxima and minima of the $t$-test values, twelve positive (increases in precipitation reconstruction) and ten negative (decreases in precipitation reconstruction) centers were picked up, i.e. 22 significant change points were discovered by our computing program (Fig. 3a).

For example, the first significant change point towards an increase in precipitation reconstruction is detected with a positive center of the contours around $5865 \mathrm{BC}$ on a 128 -year time scale. It was followed by a negative center, a decrease in precipitation, in about $5706 \mathrm{BC}$ on a little shorter time scale. Then the precipitation reconstruction increased once more around $5339 \mathrm{BC}$ on a 91-year scale and in $4606 \mathrm{BC}$ on a 304-year scale. The second decrease point is in $4313 \mathrm{BC}$ on time scale of 362 years. Then two significant increases occurred in 3770 BC and 3205 BC around time scales of 724 years. This may reveal a step-wise approximation to what appears to have been a longer period of increasing precipitation in the series. A few local centers of the contours on time scales longer than 750 years, such as in around $3400 \mathrm{BC}$, 
Table 1. Change points and Wet /Normal/Dry episodes in the Precipitation reconstruction series, and sources of collaborative evidence (TIC, $\delta^{18} \mathrm{O}$, paleoclimate references) for each episode.

\begin{tabular}{|c|c|c|c|c|c|c|}
\hline $\begin{array}{l}\text { Change- } \\
\text { years } \\
\text { (AD) }\end{array}$ & $\begin{array}{l}\text { Episode } \\
\text { Span, Grads, } \\
\text { \& Variance }\end{array}$ & $\begin{array}{l}\text { TIC } \\
\text { Change } \\
\text { years }\end{array}$ & $\begin{array}{l}\delta^{18} \mathrm{O} \\
\text { change } \\
\text { years }\end{array}$ & $\begin{array}{l}\text { Quoted } \\
\text { references }\end{array}$ & $\begin{array}{l}\text { Global } \\
\text { Change }\end{array}$ & $\begin{array}{l}\text { Climate } \\
\text { in } \\
\text { China }\end{array}$ \\
\hline$(-6000)$ & $135, \mathrm{SD}, \mathrm{s}$ & & & {$[1,2,3,4]$} & $\mathrm{w}$ & $\mathrm{W} \& \mathrm{w}$ \\
\hline$-5865 \uparrow$ & $159, \mathrm{~W}, \mathrm{~s}$ & & & {$[5,6]$} & W \& c & \\
\hline$-5706 \downarrow$ & $367, \mathrm{D}, \mathrm{s}$ & $(-5680)$ & $(-5680)$ & {$[1,2,3,4]$} & $\mathrm{w}$ & W \& w \\
\hline$-5339 \uparrow$ & $733, \mathrm{~N}, \mathrm{u}$ & & & {$[5,7]$} & $W \& c$ & $D \& c$ \\
\hline$-4606 \uparrow$ & $293, \mathrm{~W}, \mathrm{~s}$ & $-4704 \uparrow$ & $-4603 \uparrow$ & {$[5,8]$} & & $D \& c$ \\
\hline$-4313 \downarrow$ & $543, \mathrm{D}, \mathrm{s}$ & $-4236 \downarrow$ & & {$[1,2,3,4]$} & $\mathrm{w}$ & $\mathrm{W} \& \mathrm{w}$ \\
\hline$-3770 \uparrow$ & $565, \mathrm{~N}, \mathrm{u}$ & $-3646 \uparrow$ & & {$[4,5,6,9]$} & W \& c & $\mathrm{c}$ \\
\hline$-3205 \uparrow$ & $560, \mathrm{SW}, \mathrm{u}$ & $-3114 \uparrow$ & $-3249 \uparrow$ & {$[4,5,6,9]$} & & W \& w \\
\hline$-2645 \downarrow$ & $263, \mathrm{D}, \mathrm{s}$ & $-2803 \downarrow ?$ & $-2795 \downarrow$ & Fig. 24 in [4] & $\mathrm{w}$ & $\mathrm{W} \& \mathrm{w}$ \\
\hline$-2382 \uparrow$ & $500, \mathrm{~N}, \mathrm{u}$ & & $-2317 \uparrow$ & {$[1,10,11,12]$} & W \& c & W \& c \\
\hline$-1882 \downarrow$ & $465, \mathrm{~N}, \mathrm{~s}$ & & $-2043 \downarrow ?$ & {$[4,5,13]$} & & W \& w \\
\hline$-1417 \uparrow$ & $143, \mathrm{~W}, \mathrm{~s}$ & $(-1480)$ & $(-1480)$ & {$[4,5,13]$} & & W \& c \\
\hline$-1274 \downarrow$ & $196, \mathrm{SD}, \mathrm{s}$ & & & [3] & & $\mathrm{w}$ \\
\hline$-1078 \uparrow$ & $294, \mathrm{~W}, \mathrm{~s}$ & & & {$[4,5,13]$} & $\mathrm{W} \& \mathrm{c}$ & $\mathrm{D} \& \mathrm{c}$ \\
\hline$-784 \downarrow$ & $506, \mathrm{SD}, \mathrm{s}$ & $(-793)$ & $(-793)$ & [4] & D \& w & W \& w \\
\hline$-278 \uparrow$ & 736, SW, u & $-113 \uparrow ?$ & $-277 \uparrow$ & & $W \& c$ & $D \& c$ \\
\hline $458 \downarrow$ & $194, \mathrm{D}, \mathrm{s}$ & & $441 \downarrow$ & {$[3,14]$} & & \\
\hline $652 \uparrow$ & $246, \mathrm{~N}, \mathrm{u}$ & $538 \uparrow$ & $529 \uparrow$ & [5] & $\mathrm{c}$ & \\
\hline $898 \downarrow$ & $422, \mathrm{D}, \mathrm{s}$ & $794 \downarrow$ & $768 \downarrow$ & $\begin{array}{l}{[4,5,15,16,17,} \\
18]\end{array}$ & & $D \& c$ \\
\hline $1320 \uparrow$ & $171, \mathrm{~W}, \mathrm{~s}$ & & $1308 \uparrow$ & {$[1,2,4]$} & & $\mathrm{c}$ \\
\hline $1491 \downarrow$ & $219, \mathrm{D}, \mathrm{u}$ & & $1477 \downarrow$ & {$[3,14]$} & W \& c & \\
\hline $1710 \uparrow$ & $131, \mathrm{SW}, \mathrm{u}$ & $1606 \uparrow$ & & [4] & $W \& c$ & $\mathrm{sc}$ \\
\hline $\begin{array}{l}1841 \downarrow \\
(1996)\end{array}$ & $155, \mathrm{~N}, \mathrm{~s}$ & (1839) & (1839) & {$[1,2,3,4]$} & & $\mathrm{sc}$ \\
\hline
\end{tabular}

*Notes: A minus sign denotes years in BC.

$\uparrow$ indicates a change to wet; $\downarrow$ change to dry.

Numbers in the second column denote the span from a given change year to the next.

SD: Severely Dry; D: Dry; N: Normal; W: Wet; SW: Severely Wet.

s: Steady; u: Unsteady; w: Warm; c: Cold; sc: Severe cold.

( ): The beginning and ending years of the data.

[1] Benson et al. (2002), [2] Feng and Epstein (1994); [3] Hughes and Graumlich (1996); [4] Wigand (1987); [5] Madsen et al. (2001); [6] Murchison and Mulvey (2000); [7] Rhode and Madsen (1998); [8] Madsen (1985); [9] Madsen and Currey (1979); [10] Hattori (1982); [11] Long and Rippeteau (1974); [12] Stine (1990); [13] Murchison (1989); [14] Hughes and Funkhouser (1998); [15] Harper and Alder (1970); [16] Harper and Alder (1972); [17] Madsen and Simms (1998); [18] Stine (1994)

possibly result from those tree ring series covering the whole period after 6000 BC. Each change point is shown in Fig. 3b and listed in Table 1.

These 22 change points partition the unfiltered precipitation reconstruction series into 23 episodes of relatively stable mean precipitation, which are estimated from the episode averages of precipitation reconstruction for that episode (Fig. 3b). The episode averages can be sorted into 5 grades of climate-scale wetness: Severely Dry (SD) $<19.1 \mathrm{~cm} ; 19.1<$ Dry (D) $<19.6 \mathrm{~cm} ; 19.6<$ Normal (N) $<19.9 \mathrm{~cm} ; 19.9<$ Wet $(\mathrm{W})<20.3 \mathrm{~cm}$ and Severely Wet (SW) $>20.3 \mathrm{~cm}$, respectively (Table 1 ). It suggests that this region is in an arid-semiarid climatic category. Compared to
Hughes and Graumlich (1996), who analyzed the bidecadally filtered precipitation reconstruction series, the eight years labeled as extreme droughts in their Table 2 are ranked as Severe Dry or Dry episodes in our analysis. The striking multidecadal droughts between $900 \mathrm{AD}$ and $1400 \mathrm{AD}$ in Hughes and Graumlich (1996) are very similar to the Dry episode 898-1319 AD in our partition.

The 23 episodes span between 131 years (the SW-episode in $1710 \mathrm{AD}-1840 \mathrm{AD}$ ) and 736 years (the SW-episode in 278 BC-457 AD). The average duration is 348 years (Table 1). This suggests that the precipitation changes on multicentennial time scales in this analysis. This result might be technologically reasonable in the dentrochronology, because 

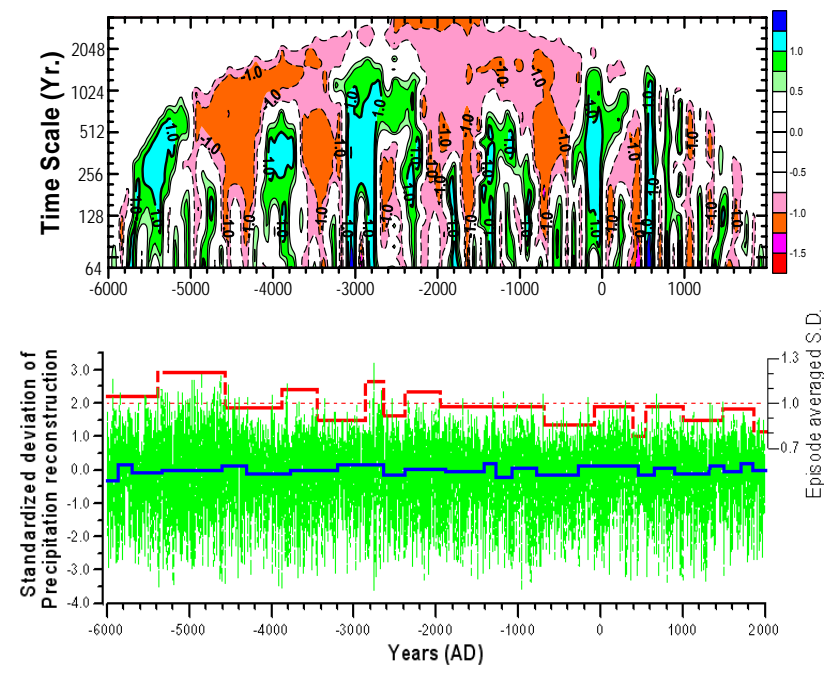

Fig. 4. (a) Contours of the index of scanning $F$-test on precipitation reconstruction series at $95 \%$ significance level. Contour interval is 0.25 but the zero-contour hidden. Solid lines denote positive values, dashed lines negative values. (b) change points and period averages of standard deviation (red line) from panel (a), change points and episode averages of precipitation (blue line) same as in Fig. 3b, and unfiltered precipitation reconstruction values (green dashed line).

the longest episode duration of 736 years is shorter than the average length of 748 years of the tree ring samples. Among the 5 grads, the SD and D-grads take over a total of 2845 years, around $35.6 \%$ of the total 7997 years, the N-grad occupies the sum of 2664 years, 33.3\%, and the W-SW grads cover 2487 years in sum, i.e. $31.1 \%$ of the total 7997 years.

\subsection{Results from the scanning $F$-test}

The scanning $F$-test (Eq. 4 ) of the precipitation reconstruction series was calculated on the same time scales as in Fig. 3. Figure 4a shows many frequent variations on short time scales. On time scales longer than 128 years, however, seven positive (increases of subseries variances) and eight negative (decreases of subseries variances) significant changes were detected, with local maxima and minima in the contours (Fig. 4a). The change years are usually different from those in the first moment (subseries means). Generally, a smaller standard deviation is featured, which means a steadier climate, in the latter period after $2000 \mathrm{BC}$, than that in the earlier period. We may characterize each episode as a steady or unsteady feature by combining these results with those episodes that were partitioned in Sect. 4.1. For instance, the episode $5339 \mathrm{BC}-4607 \mathrm{BC}$ is featured as unsteady (symbolized as "u" in the second column of Table 1), because a large standard deviations (Fig. 4b) corresponds to that. The feature steady (symbolized as "s" in the second column of Table 1) for the episodes $4606 \mathrm{BC}-4314 \mathrm{BC}$ and 4313 BC-3771 BC follow, because smaller standard deviation (Fig. 4b) coincides with them comparatively, and so on.
Statistically from Table 1, there are 8 steady in proportion to 1 unsteady for a total of 9 episodes in the SD-D grads, 5 steady in ratio to 3 unsteady for a total of 8 episodes in the W-SW grads, while 2 steady comparing to 4 unsteady of 6 episodes in the $\mathrm{N}$-grad. Why the W-SW grads have a slightly higher ratio of unsteady episodes than those in the SD-D grads, is perhaps partly influenced by the tree growth, which is not perfectly removed in the reconstruction process, because it results in a high mean (increased tree ring growth or width) which is naturally related to a high variance (increased growth variance) by factors that are internal to tree growth, not to climate (Cook and Peters, 1997). However, five steady of the eight high-mean episodes W-SW are still dominant. This implies here that the $F$-test of the precipitation reconstruction can reflect mainly the significant climatechange information.

\section{Comparison with sedimentary records}

This section presents some approximately synchronous changes in subseries means in the precipitation reconstruction with those in the TIC or $\delta^{18} \mathrm{O}$ records, which are built from cored sediments of Pyramid Lake, Nevada (Benson et al. 2002). Their coherency analyses of subseries-variance changes are not included, because there are multi-millennial trends in both the TIC and $\delta^{18} \mathrm{O}$ series, especially in the earlier period from $5680 \mathrm{BC}$ to $1480 \mathrm{BC}$ (see Fig. 7). Benson et al. (2002) stated that the lake volume fluctuations, as well as fluctuations of the $\delta^{18} \mathrm{O}$ or TIC records are not simply linearly correlated. In general, droughts lead $\delta^{18} \mathrm{O}$ to increase initially as the lake's volume decreases, but the steady-state value of $\delta^{18} \mathrm{O}$ for a long drought period is much smaller than that in a wetter period. During wet episodes, Pyramid Lake receives more inflows from its source, the Truckee River, and thus has higher $\delta^{18} \mathrm{O}$ values. TIC is expected to parallel changes in $\delta^{18} \mathrm{O}$ for long dry and wet periods.

The coherency of significant changes in the precipitation reconstruction series with those in the TIC series for earlier years (Fig. 5e) shows four positive coherency (in-phase), centers around $4700 \mathrm{BC}$ and $4230 \mathrm{BC}$ on a 256 -year scale, in $3680 \mathrm{BC}$ on a 2048-year scale, and in $3100 \mathrm{BC}$ on a 512-year scale, respectively, despite the presence of three weak negative coherency centers. Some but not all of the change points in the individual series (Figs. 5a and c) coincide closely. For instance, the TIC change points (centers in Fig. 5a) in $4704 \mathrm{BC}, 4236 \mathrm{BC}, 3646 \mathrm{BC}$ and $3114 \mathrm{BC}$ are close to those in 4606BC, 4313BC, 3770BC, and 3205BC in the precipitation reconstruction series (centers in Figs. 3a or 5c), respectively, by differences within 150 years. The last weak change around 2803 BC in TIC (Fig. 5a) preceeded that in the precipitation reconstruction series by 158 years, so that the coherency is not obvious; we listed this in Table 1 with a question mark. Two possible explanations for the differences in significant change years between the two series are firstly, 


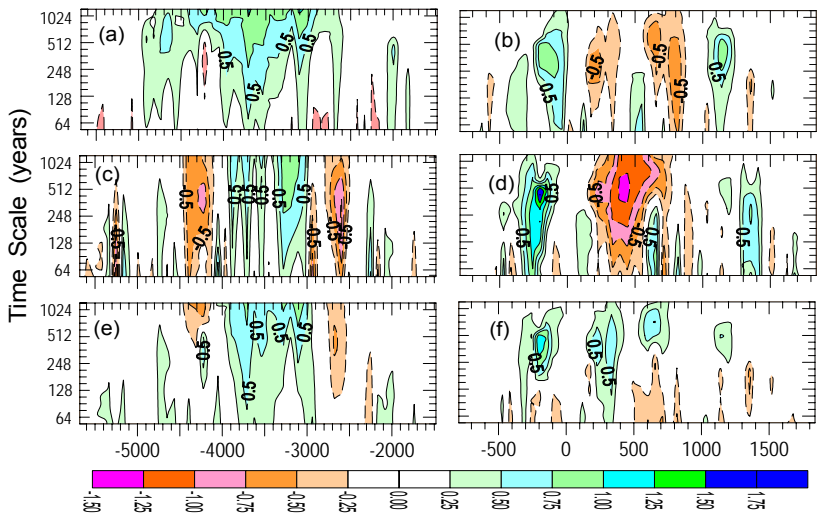

Fig. 5. Contours of the normalized scanning $t$-test at a $90 \%$ significance level: (a-b) for the TIC series from Pyramid Lake sediments (c-d) for the precipitation reconstruction series at same year/timescale grids as in panels (a-b); (e-f) the coherency of abrupt changes between panels (a) and (c), (b) and (d), respectively. Contour interval is 0.25 but contour zero hidden. Solid lines denote positive values, dashed lines negative values.

chronological errors, especially in the sediment records comparing to the tree ring reconstruction, and secondly, different locations where the data were collected from.

For later years, Fig. $5 \mathrm{f}$ displays 5 positive coherency centers at $200 \mathrm{BC}, 190 \mathrm{AD}, 330 \mathrm{AD}, 640 \mathrm{AD}$ and $870 \mathrm{AD}$ (comparatively weaker) on scales longer than 300 years, except for some weak, negative coherency centers on time scales shorter than 300 years, i.e. significant changes in the TIC series are mainly in-phase with those in the precipitation reconstruction series on time scales longer than 300 years, while anti-phased are on scales shorter than 300 years. This result agrees with Benson et al. (2002), as mentioned above in the first paragraph of this section. The TIC change points (Fig. 5b) in 113 BC, 538 AD, 794 AD and 1606 AD are approximately close to those in the precipitation reconstruction at $278 \mathrm{BC}, 652 \mathrm{AD}, 898 \mathrm{AD}$ and $1710 \mathrm{AD}$, respectively (Table 1 or Fig. 7). As the TIC change year 113 BC occurred 165 years later than the change point in $278 \mathrm{BC}$ in the precipitation reconstruction, we list it in Table 1 with a question mark. The TIC change year $214 \mathrm{AD}$, which preceded the change point $458 \mathrm{AD}$ in the precipitation reconstruction by 244 years, is not listed in Table 1.

Similarly, Fig. 6c demonstrates the coherency of significant changes between the $\delta^{18} \mathrm{O}$ (Fig. 6a) and the precipitation reconstruction (see Fig. 5c) for the earlier period, and unmasks five weak, positive coherency centers around $4620 \mathrm{BC}-3710 \mathrm{BC}, 3300 \mathrm{BC}, 2750 \mathrm{BC}$ and $2240 \mathrm{BC}$, respectively. The coherency here is weaker than that between the TIC and the precipitation reconstruction series (Fig. 5e), because changes in the $\delta^{18} \mathrm{O}$ series itself are weaker. However, the change points detected in the $\delta^{18} \mathrm{O}$ series in $4603 \mathrm{BC}-$ 3249 BC, 2795 BC and 2317 BC (Fig. 6a), are comparable to those in the precipitation reconstruction series (Table 1 or
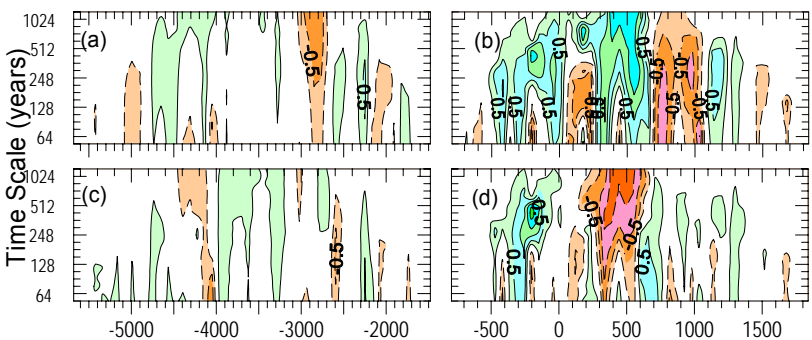

Fig. 6. (a-b) as same as in Figs. 5a-b but for the $\delta^{18} \mathrm{O}$ series; (c-d) as same as in Figs. 5e-f but for coherency between the $\delta^{18} \mathrm{O}$ and the precipitation reconstruction series.

Fig. 7). In addition, the $\delta^{18} \mathrm{O}$ change point in $2043 \mathrm{BC}$ was 161 years earlier than that in the precipitation reconstruction (Table 1 or Fig. 7), the coherency index (Fig. 6c) is negative in sign, so we list it with a question mark in Table 1. Because the time scale of the positive coherency center in $3710 \mathrm{BC}$ (Fig. 6c) is too long to identify changes in multi-centenary time scales in the $\delta^{18} \mathrm{O}$ series, no corresponding change year is listed in Table 1.

For the later period, in Fig. 6d, most coherency centers are positive (in-phased changes) on longer time scales, except for a negative coherency center during 300-500 AD, while more negative centers (anti-phased changes) than positive ones appear on shorter time scales. This feature basically coincides with the description by Benson et al. (2002), as quoted in the first paragraph of this section. Though the coherency is obviously weaker than that in Fig. 5f, there are six inphased changes around $200 \mathrm{BC}, 230 \mathrm{AD}, 640 \mathrm{AD}, 890 \mathrm{AD}$, $1320 \mathrm{AD}$ and $1500 \mathrm{AD}$ on scales longer than 100 years. The abrupt changes $277 \mathrm{BC}, 441 \mathrm{AD}, 529 \mathrm{AD}, 768 \mathrm{AD}, 1308 \mathrm{AD}$ and $1477 \mathrm{AD}$ for the $\delta^{18} \mathrm{O}$ series may correspond to those in the precipitation reconstruction series (Table 1 and Fig. 7).

Further comparisons, by calculating the episode averages for each series based on the detected change points for that series and by using a 101-year Gaussian filter to low-pass filter each series, are illustrated in Fig. 7. An obvious difference is that the millennial-scale trends in both the TIC and $\delta^{18} \mathrm{O}$ series in the earlier period, from $5680 \mathrm{BC}$ to $1480 \mathrm{BC}$, are much more apparent than that in the precipitation reconstruction. As mentioned in Sect. 3, the precipitation series is reconstructed from tree rings with an average length shorter than 750 years and with a standardization of every tree ring sample, which may preclude any millennial-scale trend in the precipitation reconstruction series.

Even so, there are common features in the episode averages and smoothed data of the three series. In the middle Holocene, the Dry episode in 5706-5340 BC, the Wet episode in 4606-4314 BC, the Severely Wet episode in 3205-2646 BC and the Dry episode in 2645-2383 BC identified in the partitioned precipitation reconstruction series (Fig. 7a) have rough equivalents to those in the other two 

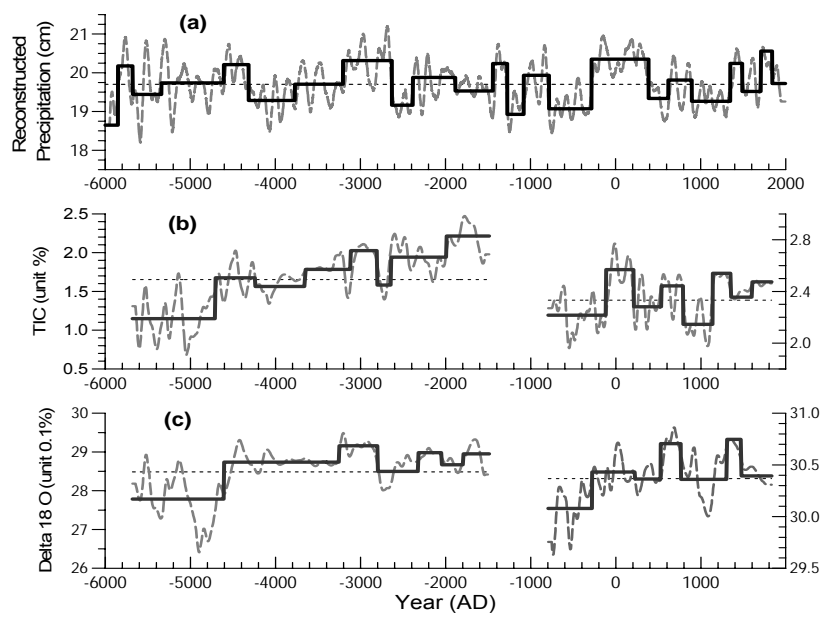

Fig. 7. The change points and episode averages (solid line), 101year Gaussian filter (dashed line) and averages over the entire time series (dotted line) in the three series: (a) same as in Fig. 3b; (b) for the TIC and (c) for the $\delta^{18} \mathrm{O}$ series from sediment cores in Pyramid Lake.

series (Figs. 7b and c). The Dry episode in 4313-3771 BC and the Normal episode in 3770-3206 BC in the precipitation reconstruction have analogs in the TIC series, while the Normal episode in 2382-1883 BC and 1882-1418 BC approximate those in the $\delta^{18} \mathrm{O}$ series. Only the Normal episode in 5339-4607 BC is not collaborated by either the TIC or $\delta^{18} \mathrm{O}$ series.

During the late Holocene, the Severely Dry episode in 784 279 BC, the Severely Wet episode in 278 BC-457 AD, the Dry episode in 458-651 AD, the Normal episode in 652897 AD and the Dry episode in 898-1320 AD are similar among the three series (Fig. 7). The Wet episode in 13201490 AD and the Dry episode in 1491-1709 AD in the precipitation reconstruction (Fig. 7a) are roughly comparable to those in the $\delta^{18} \mathrm{O}$ series (Fig. 7c). The Severely Wet episode in 1710-1840 AD in the precipitation reconstruction (Fig. 7a) is similar to that in the TIC series (Fig. 7b).

Interestingly, the period from 1479 to $794 \mathrm{BC}$, in which the TIC and $\delta^{18} \mathrm{O}$ series were disconnected between the piston cores PLC98-4 and PLC 97-1, is identified as a period of very strong changes on short time scales in the precipitation reconstruction (Fig. 7a).

\section{Verification with related studies}

Although the precipitation reconstruction is for the Climate Division 3 in Nevada, the tree ring samples composed of the unfiltered precipitation reconstruction were collected from the White Mountains in California. Moreover, because the significant changes identified in this paper are presented on multi-centennial time scales, climate changes usually occurred in a large geographical area, especially during dry periods. Thus, we can consider the changes in the precipitation reconstruction series as an epitome of what happened in the western USA. Given this, we may try to use previously published archaeological reports about that region to further collaborate our partition results.

Some related papers published in the last 30 years have examined climatic fluctuations in precipitation or airtemperature in the western USA based on analyses of sediments, pollen, vegetation and tree rings, besides Hughes and Graumlich (1996) and Benson et al. (2002). For example, Madsen et al. (2001) analyzed remains of small animals from stratified raptor deposits, together with fossil woodrat midden samples, to partition climate epochs in the eastern Great Basin during the late Pleistocene and Holocene. Grayson (2000) interpreted a decrease in small mammal fauna in the Bonneville Basin of north central Utah as evidence of a dry climate during the Middle Holocene. Benson et al. (1997) investigated $\delta^{18} \mathrm{O}$ and TIC changes in Owens Lake of the Great Basin for the period from 17000 BP to 4500 BP. Feng and Epstein (1994) studied a hydrogen isotope time series covering the last 8000 years from Bristlecone Pines in the White Mountains of California. Stine (1994) synthesized data from relict tree stumps in Mono Lake and Tenaya Lake in California, and in southernmost Patagonia in South America $\left(48^{\circ} \mathrm{S}-\right.$ $50^{\circ} \mathrm{S}$ ), to determine extreme and persistent drought in California and Patagonia during medieval times. Stine (1990) presented lake-level fluctuations in Mono Lake, California, for the last 4000 years. Wigand (1987) described the changes in vegetation for the last 6200 years at Diamond Pond in the eastern Oregon desert. However, no report of variance changes was found in these research studies, so we discuss only changes in episode means in this section.

For comparison to these studies, we take 1950 as the present year to convert years before present (BP) into calendar years (BC/AD). As mentioned above, sediment cores and pollen records have a dating accuracy of about $50-100$ years, even more in multi-millennial chronology. The records from cores may also be biased in reflecting the extreme events of climatic droughts or floods, rather than the average conditions over multi-centennial periods. These will make the alignment of dates only approximate and for rough, but useful, verifications of the climate situations.

The middle Holocene period from $6000 \mathrm{BC}$ to $3300 \mathrm{BC}$ is commonly recognized to be dry and warm in the Great Basin area, which covers most of Nevada and neighboring regions of southeastern Oregon, eastern and southeastern California, and western Utah (Benson et al., 2002; Madsen et al., 2001; Grayson, 2000; Feng and Epstein, 1994; Wigand, 1987). Five of the eight extreme droughts were distinguished around 5970, 5881, 5591, 4058 and 3948 BC, respectively, by Hughes and Graumlich (1996). This epoch also coincides with the global first long warm phase during the last ten thousand years, known as the Europe Climatic Optimum period (Asakura, 1991). In our analysis (Table 1), the Severely Dry episode in 6000-5866 BC and Dry episodes 
in 5706-5340 BC, 4313-3771 BC occurred in this period. Moreover, the above-mentioned five of the eight years of extreme droughts in Hughes and Graumlich (1996) are included in these three Dry episodes. In China, the climate in this period also featured warm and wet conditions, glaciers retreated in the western mountains while the desert shrunk in Inner-Mongolia. The Lake Daihai $\left(112^{\circ} 39^{\prime} \mathrm{E}, 40^{\circ} 30^{\prime} \mathrm{N}\right)$, for example, was four times the area of that at present, and the "Painted Pottery Literature" developed in the middle-reaches of the Yellow River in China during this period (Ye and Chen, 1992).

However, there exist comparatively short wet spells during this long warm phase. For instance, most glaciers on the Earth progressed around 5400 BC (Goodess et al., 1992). Around $5700 \mathrm{BC}$ the Great Salt Lake level had risen up to its normal level at about $1283 \mathrm{~m}$, which was estimated from marsh deposits (Madsen et al., 2001; Murchison and Mulvey, 2000). This may confirm the Wet episode in 5865-5707 BC in our Table 1. There is a good fit to the Normal episode in 5339-4607 BC (Table 1) by Madsen et al. (2001), who quoted that between $5450 \mathrm{BC}$ and $4750 \mathrm{BC}$ (Rhode and Madsen, 1998) single-leaf pinyon nut hulls first appeared in the archaeological record from the Danger Cave (see Fig. 1) in the west of the Great Salt Lake Desert, suggesting a wetter climatic environment than earlier. Other reports by Madsen et al. (2001) and Madsen (1985) state that a spell of greater effective moisture is indicated by a pronounced increase in the abundance of pine at the Potato Canyon Bog (see Fig. 1) in central Nevada between 4550 BC and 4050 BC; this agrees with the Wet episode in 4606-4314 BC (Table 1). In China, two comparatively low magnetization-rates were recorded around $5330 \mathrm{BC}$ and $4700 \mathrm{BC}$ in the loess sediments at Baxie $\left(103^{\circ} 24^{\prime} \mathrm{E}, 36^{\circ} 42^{\prime} \mathrm{N}\right)$ in Gansu province, denoting a relatively cold and arid climate (Ye and Chen, 1992). Fang et al. (2004) summarized cold events around 5450 BC, 4750 BC and a cold period from $4450 \mathrm{BC}$ to $4250 \mathrm{BC}$ in China based on a statistical analysis of cold events or periods based on 97 investigation articles published before.

Wigand (1987) classified the phase from 3510 to $1850 \mathrm{BC}$ into the first wet period that heralded the end of the midHolocene drought; it is evidenced that sagebrush pollen increases in the perennial Diamond Pond (Fig. 1) in the eastern Oregon desert, and that the littoral and aquatic plant macrofossils and mollusk shells appeared with sudden abundance shortly before 3510 BC at Malheur Maar (Fig. 1) in the east of Oregon. Madsen et al. (2001) stated that between 3350 BC and $2450 \mathrm{BC}$, there was an increase in artiodactyl fecal pellets at Homestead Cave (Fig. 1) in Utah, and quoted a mean lake-level elevation of $1280 \mathrm{~m}$ or lower in the Great Salt Lake (Murchison and Mulvey, 2000) and markedly cooler conditions after 3350 BC at Snowbird Bog (Fig. 1) in Utah (Madsen and Currey, 1979). These suggest a normal or wetter climate, and lend some credence to the Normal episode in 3770-3206 BC and the Wet episode in 3205-2646 BC in our Table 1. Meanwhile, most glaciers on the Earth devel- oped again between $3500 \mathrm{BC}$ and $2400 \mathrm{BC}$ (Goodess et al., 1992). Fang et al. (2004) identified a cold period from 4050 to $3450 \mathrm{BC}$ and a cold event in $2950 \mathrm{BC}$ in China.

For the Dry episode in 2645-2383 BC in our Table 1, Fig. 24 in Wigand (1987) shows decreases in the juniper pollen percentage and in the ratio of grass to sagebrush pollen, which mark a drier climate during this spell, though an accompanying description was lacking in the text.

Benson et al. (2002) summed up the findings by Long and Rippeteau (1974), Hattori (1982), Wigand and Mehringer (1985), Grayson (1993), Stine (1990), and others, that there was a wet phase from $2300 \mathrm{BC}-1700 \mathrm{BC}$. This is consistent with the Wet episode in $2382 \mathrm{BC}-1883 \mathrm{BC}$ in Table 1. Madsen et al. (2001) sorted the period from $2450 \mathrm{BC}$ to $1000 \mathrm{BC}$ as cooler with higher water levels in the lakes, of which the Great Salt Lake level peaked up to $1284 \mathrm{~m}$ in $1450 \mathrm{BC}$ (Murchison, 1989), and the following period from $1000 \mathrm{BC}$ to $450 \mathrm{BC}$ was regarded as much wetter and cooler. Wigand (1987) found that the period from $2050 \mathrm{BC}$ to $450 \mathrm{BC}$ was very wet with the deepest late-Holocene pond (Diamond pond) around $1750 \mathrm{BC}$. These descriptions have some correspondence with the Normal episode in 1882 BC-1418 BC, the Wet episodes in $1417 \mathrm{BC}-1275 \mathrm{BC}$ and $1078 \mathrm{BC}-$ 785 BC in our Table 1, of which the Wet episode in 1078 BC$785 \mathrm{BC}$ also coincided roughly with the glacier advances in the Northern Hemisphere (Goodess et al., 1992).

Bond et al. (1997) found two cold events around $2350 \mathrm{BC}$ and $850 \mathrm{BC}$ in the North Atlantic by analyzing concentration of lithic grains and petrologic tracers in Holocene sediments of two cores from opposite sides of the North Atlantic. In China, there were cold periods from $2050 \mathrm{BC}$ to $1750 \mathrm{BC}$, from $1450 \mathrm{BC}$ to $1250 \mathrm{BC}$ and from $950 \mathrm{BC}$ to $750 \mathrm{BC}$ (Fang et al., 2004), in which the Hanshui River had frozen twice in 903 BC and 897 BC, respectively (Zhu, 1979).

The Severely Dry episode of 1274 BC-1079 BC (Table 1) contains the year $1251 \mathrm{BC}$, one of the eight extreme dry years found by Hughes and Graumlich (1996). No report of cold events was presented for the years between $1200 \mathrm{BC}$ and 1000 BC by either Bond et al. (1997) or by Fang et al. (2004). It was known as an optimal period of a warm and wet environment in China (Zhu, 1979), and was found that there were elephants in the north of Henan province, south of the Yellow River in eastern China during the spell from $1300 \mathrm{BC}$ to 1100 BC (Ye and Chen, 1992).

Though the Severely Dry episode in 784 BC-279 BC in Table 1 diverges from the generally wet conditions for this period suggested by Madsen et al. (2001) and Wigand (1987), a brief but significantly drier period after $650 \mathrm{BC}$ is noted, in which it was reflected by less-abundant floating and submerged aquatic plants at Diamond Pond (Wigand, 1987). During this time most glaciers on the Earth receded (Goodess et al., 1992). In China, the climate returned to a warm phase from $700 \mathrm{BC}$ to $20 \mathrm{AD}$ (Zhu, 1979), but with a relative cold period from 350 to $250 \mathrm{BC}$ (Fang et al., 2004). 
The Dry episodes of 458 AD-651 AD and 1491 AD1709 AD in Table 1 are also recognizable as dry periods by Hughes and Graumlich (1996), as well as by Hughes and Funkhouser (1998), who showed that there was a greater incidence of intense persistent moisture deficits after $400 \mathrm{AD}$ and before $1500 \mathrm{AD}$ in the Great Basin of North America. However, a cold event in $550 \mathrm{AD}$ in the North Atlantic was reported by Bond et al. (1997).

For the Normal episode in 652 AD-897 AD in Table 1, Madsen et al. (2001) give evidence that around 750 AD a kind of fish, at Utah chub, thrived and that hackberry endocarps were common, which indicates significantly moister conditions in the Homestead Cave vicinity. During this period most glaciers advanced again on the Earth, and the summer in Europe and America was comparatively cold (Goodess et al., 1992). In China, however, it was relatively warm between $600 \mathrm{AD}$ and $1000 \mathrm{AD}$, droughts occurred in the middle-reaches of Yellow River and no snow and ice were seen in Xi'an city, the Capital of Shanxi province, for several winters (Zhu, 1979; Ye and Chen, 1992), but Fang et al. (2004) concluded a cold event around 850 AD.

Previous investigations also appear to be consistent with the Dry episode in 898 AD-1319 AD in Table 1. For example, Stine (1994) designates the years from $900 \mathrm{AD}$ to $1200 \mathrm{AD}$ as a period of extreme and persistent drought in California, based on analysis of the tree rings at Mono Lake (Fig. 1). Madsen et al. (2001) summarized that between $1250 \mathrm{AD}$ and $1320 \mathrm{AD}$, widespread droughts caused people to shift to full-time foraging in the Bonneville Basin (Madsen and Simms, 1998), and the period from $950 \mathrm{AD}$ to $1320 \mathrm{AD}$ may have been one of the warmest and driest phases in the Holocene (Harper and Alder, 1970, 1972). Wigand (1987) concluded that around 1250AD and $1450 \mathrm{AD}$ there were two major droughts indicated by increases in greasewood values in Diamond Pond sediments.

Wigand's drought in $1450 \mathrm{AD}$ is just earlier than the Dry episode in 1491 AD-1709 AD in our Table 1 by less than 50 years, which might be considered as to coincide with each other. The period from $900 \mathrm{AD}$ to $1300 \mathrm{AD}$ is called the Medieval Warm Epoch in the global change literature, the second warm phase during the last ten thousand years (Asakura, 1991). Most glaciers on the Earth retreated during this phase (Goodess et al., 1992). In China, however, the average temperature was a little lower than at the present, though undergoing shorter fluctuations from warm (600 AD to $1000 \mathrm{AD}$ ), to cold (1000 AD to $1200 \mathrm{AD}$ ), to warm again (1200 AD to $1300 \mathrm{AD}$ ), and to another cold (1301 AD to $1600 \mathrm{AD}$ ) (Zhu, 1979), so that Fang et al. (2004) classified the period from $1150 \mathrm{AD}$ to $1850 \mathrm{AD}$ as a cold phase.

There is collaborative evidence for the Severely Wet episode in 1710 AD-1840 AD in Table 1. Wigand (1987) discerned $1650 \mathrm{AD}-1800 \mathrm{AD}$ as wet with abundant juniper and grass pollen. Feng and Epstein (1994) concluded that there was a cool climate spell peaking between $1700 \mathrm{AD}$ and 1900 AD. This period corresponds to the Little Ice Age in
Europe, and the glaciers advanced on the Earth (Goodess et al., 1992). Bond et al. (1997) also reported a cold event around $1650 \mathrm{AD}$ in the North Atlantic. China also experienced its coldest phase from $1601 \mathrm{AD}$ to $1899 \mathrm{AD}$ during the last 5000 years (Zhu, 1979; Ye and Chen, 1992).

It is easy to understand that the last episode since $1841 \mathrm{AD}$ is in the Normal category (Table 1), because the precipitation reconstruction is based on a regression analysis between the tree ring records and the precipitation observations in the Nevada Climate Division 3 during the same period from 1932 AD to 1979 AD (Hughes and Graumlich, 1996). This episode roughly corresponds to the third warm phase after $1850 \mathrm{AD}$ in the global change during the last ten thousand years (Asakura, 1991). The declining trend (increase dryness) in the low-pass filtered curve of the precipitation reconstruction (Fig. 7a) for the last 50 years might reflect the global warming in the last century. The warming in China for the last 50 years has appeared obviously in the winters and in the Northern China (Qing, 2005).

The above-mentioned collaborating evidence is listed in the fifth column as "quoted references" of Table 1. Only the Severely Wet episode in 278 BC-457 AD is not collaborated by related publications, but it is close to similar changes which appeared in the $\delta^{18} \mathrm{O}$ and TIC series. Also, the glaciers mostly advanced on Earth in this period (Goodess et al., 1992). China transformed into the second cold phase (20 AD to $600 \mathrm{AD}$ ) during the last 5000 years (Zhu, 1979), and Fang et al. (2004) reported a cold period from $150 \mathrm{AD}$ to $550 \mathrm{AD}$ in China.

\section{Summary}

Both algorithms, the scanning $t$-test and the scanning $F$-test, were applied to the 8000-year series of annual precipitation reconstruction from tree rings in the southwestern USA. The precipitation reconstruction is calibrated in regression of tree ring chronology to annual (prior July through current June) precipitation observations in the region of the Climate Division 3 in Nevada. Based on the scanning $t$-test, twentytwo significant change points were identified in the subseries means and 23 wetness episodes were partitioned in the precipitation reconstruction series. All episodes were classified into 5 grades according to the episode mean values of the precipitation reconstruction and are characterized in steady or unsteady features by combining with the results from the scanning $F$-test, which detects significant changes in subseries variances or standard deviation.

The coherency detection of significant changes in the subseries mean was employed to compare the episodes partitioned in the precipitation reconstruction series with those in the TIC and $\delta^{18} \mathrm{O}$ records, which were derived from Pyramid Lake sediment cores in the northwest of Nevada. The algorithm was modified to accommodate unequal time intervals in the TIC and $\delta^{18} \mathrm{O}$ time series. It is shown that 13 of 
the 23 wetness episodes in the precipitation reconstruction are approximately coincident with those in the TIC and $\delta^{18} \mathrm{O}$ records.

Collaborating evidence from related paleoclimate studies was found for 22 of the 23 episodes. The related paleoclimate studies involve analyses of tree rings, pollen content, vegetation history, animal remains, and the TIC and $\delta^{18} \mathrm{O}$ records in sediment cores collected from Nevada and vicinity states. All wetness episodes, which were partitioned in the precipitation reconstruction series, are reasonably confirmed either by coherency of significant changes to those in the TIC and $\delta^{18} \mathrm{O}$ records in Pyramid Lake sediments or by related previously published investigations (Table 1).

There seems to be a good relationship of the wetness episodes in the precipitation reconstruction series with the periods in the global change: the warm and dry episodes in the southwestern USA usually coincide with the global warm phases, while the cold and wet episodes in the southwestern USA are often associated with the global cold epochs. Scientists interpreted the global warm phases before $1850 \mathrm{AD}$ as controlled by the geomagnetic effect and changes in solar activities, as well as the interactions between the atmosphere and ocean - ice - land, while the last warming period after $1850 \mathrm{AD}$, especially for the last 50 years, is affected by human activities - mostly fossil fuel combustion (Eddy, 1976; Hood and Jirikowic, 1990; Goodess et al., 1992; IDAG, 2005).

Persistent droughts and pluvials over the Plains and western part of the USA were recognized as being ultimately driven by the tropical Pacific SST variations (Seager et al., 2005). The IDAG (International Ad Hoc Detection and Attribution Group, Zwiers et al., 2005) summarized that the combination of La Niña and a reduced moisture supply from the Gulf of Mexico likely led to the severe North American drought. Ropelewski and Halpert (1986) and Hidalgo and Dracup (2003) concluded that in general, southwestern U.S. cold season precipitation tends to be wetter than normal during El Niño events (negative phase of the Southern Oscillation), while drier than normal during La Niña events (positive phase of the Southern Oscillation). But the opposite effect is observed for the northwestern USA, creating a bipolar response between the two regimes.

Climate changes in China are similar to the global change in general, but a little complicated in the some detailed episodes, such as a few spells during the period from $600 \mathrm{AD}$ to $1600 \mathrm{AD}$. The effects of the El Niño and La Niña events on climate variation in China are also more complex than that in the southwestern USA (Qing, 2005).

This work verifies that the tree ring series provide a valuable record of precipitation changes on climatic scales in the southwestern USA, except perhaps for multi-millennial trends, which are more obvious in the TIC and $\delta^{18} \mathrm{O}$ records. It also suggests that the algorithms of the scanning $t$-test, the scanning $F$-test and the coherency detection produce objective detection of multi-scale significant changes in both sub- series means and subseries variances in a long-time series, and for in-phase or out-phase significant changes between two time series, even when they are sampled on unequal time intervals.

Acknowledgements. This work is supported by the China Meteorological Administration in the project of climate change, and by the University of Hawaii pursuant to National Oceanic and Atmospheric Administration Award No. NA67RJ0154. The authors thank very much R. Mendelssohn and F. Schwing for many helps and advices in the research, thank deeply M. Hughes for providing web site to download the unfiltered reconstruction data, and thank L. Benson for kindly providing the data of the TIC fraction and $\delta^{18} \mathrm{O}$ records, also thank two referees for helpful advices to improve the paper.

Topical Editor F. D'Andrea thanks M. Timonen and another anonymous referee for their help in evaluating this paper.

\section{References}

Asakura, S. (translated by Zhou, L.): Climatic abnormality and environmental destruction (in Chinese), Meteorological Press, Beijing, 1991.

Benson, L., Burdett, J., Lund, S., et al.: Nearly synchronous climate change in the Northern Hemisphere during the last glacial termination, Nature, 388, 263-265, 1997.

Benson, L., Kashgarian, M., Rye, R., et al.: Holocene multidecadal and multicentennial droughts affecting Northern California and Nevada, Quat. Sci. Rev., 21, 659-682, 2002.

Bond, G., Showers, W., Cheseby, M., et al.: A pervasive millennialscale cycle in North Atlantic Holocene and glacial climates, Science, 278(14), 1257-1266, 1997.

Cook, E. R. and Peters, K.: Calculating unbiased tree ring indices for the study of climatic and environmental change, The Holocene, 7(3), 359-368, 1997.

Cramer, H.: Mathematical Method of Statistics. Princeton University Press, Princeton, N.J., USA, 1946.

Eddy, J. A.: The Maunder Minimum, Science, 192(4245), 11891202, 1976.

Fang, X., Ge, Q., and Zheng, J.: Cold events in Holocene and millennial period of climatic changes (in Chinese), Prog. Nat. Sci., 14(3), 456-461, 2004.

Feng, X. and Epstein, S.: Climatic implications of an 8000-year hydrogen isotope time series from Bristlecone Pine trees, Science, 265, 1079-1081, 1994

Goodess, C. M., Palutikof, J. P., and Davies, T. D.: The nature and causes of climate change, Belhaven Press, London, 1992.

Goossens, C. and Berger, A.: How to recognize an abrupt climatic change?, in: Abrupt Climatic Change. Evidence and Implications, NATO ASI series C: Mathematical and Physical Sciences, edited by: Berger, W. H. and Labeyrie, L. D., vol. 216, D. Reidel, Dordrecht, pp. 31-46, 1987.

Grayson, D. K.: The Deserts Past, a Natural Prehistory of the Great Basin, Smithsonian Institution Press, Washington, 1993.

Grayson, D. K.: Mammalian responses to Middle Holocene climatic change in the Great Basin of the western United States, J. Biogeography, 27, 181-192, 2000.

Harper, K. T. and Alder, G. M.: The macroscopic plant remains of the deposits of Hogup Cave, Utah, and their paleoclimatic impli- 
cations, in: Hogup Cave, edited by: Aikens, C. M., University of Utah Anthopological Papers 93, Salt Lake City, pp. 215-240, 1970.

Harper, K. T. and Alder, G. M.: Paleoclimatic inferenves concerning the last 10000 years from a Resampling of Danger Cave, Utah, in: Great Basin Cultural Ecology: a Symposium, edited by: Fowler, D. D., Desert Research Institute Publications in the Social Sciences, Reno, 8, 13-23, 1972.

Hattori, E. M.: The archaeology of Falcon Hill, Winnemucca Lake, Washoe County, Nevada, Nevada State Museum Anthropological Papers No. 18, 1982.

Hidalgo, H. G. and Dracup, J. A.: ENSO and PDO Effects on Hydroclimatic Variations of the Upper Colorado River Basin, J. Hydrometeorol., 4, 5-23, 2003.

Hood, L. L. and Jirikowic, J. L.: Recurring variations of probable solar origin in the atmospheric $\Delta^{14} \mathrm{C}$ time record, Geophys. Res. Lett., 17(1), 85-88, 1990.

Hughes, M. K. and Graumlich, L. J.: Climatic variations and forcing mechanisms of the last 2000 Years, volume 141, MultiMillennial dendroclimatic studies from the western United States, NATO ASI Series, 109-124, 1996.

Hughes, M. K. and Funkhouser, G.: Extremes of moisture availability reconstructed from tree rings for recent millennia in the Great Basin of Western North America, in: The Impacts of Climate Variability of Forests, edited by: Beniston, M. and Innes, J., Springer-Verlag, Berlin, p. 99-107, 1998.

IDAG (The International Ad Hoc Detection and Attribution Group, Zwiers, F, Barnett, T., Hegerl, G., et al.): Detecting and Attributing External Influences on the Climate System: A Review of Recent Advances, J. Climate, 18, 1291-1314, 2005.

Hammersley, J. M.: Discussion of papers, J. Roy. Statist. Soc., 8, 91, 1946.

Hughes, M. K. and Graumlich, L. J.: Multi-Millennial Nevada Precipitation Reconstruction. International tree ring Data Bank, IGBP PAGES/World Data Center-A, for Paleoclimatology Data Contribution Series \#2000-049. NOAA/NGDC Paleoclimatology Program, Boulder CO, USA, 2000.

IPCC: Climate Change 2001: The Scientific Basis. Contribution of Working Group I to the Third Assessment Report of the International Panel on Climate Change, Cambridge, U.K., edited by: Houghton, J. T., Ding, Y., Griggs, D. J., Noguer, M., Van der Linden, P. J., Dai, X., Maskell, K., and Johnson, C. A., Cambridge University Press, 2001.

Jiang, J., Fraedrich, K., and Zou, Y.: A scanning t test of multiscale abrupt changes and its Coherence analysis, Chinese J. Geophys. (in Chinese), 44(1), 31-39, 2001.

Jiang, J., Gu, X., and You, X.: An analysis of Significant changes in monthly streamflow at Yichang section of the Changjiang River (in Chinese), J. Lake Scieces, 15(Supplement), 131-137, 2003.

Jiang, J., Mendelssohn, R., Schwing, F., and Fraedrich, K.: Coherency detection of Multiscale significant changes in historic Nile flood levels, Geophys. Res. Lett., 29(8), 112-1-112-4, 2002.

Karl, T. R. and Riebsame, W. E.: The identification of 10- to 20year temperature and precipitation Fluctuations In the contiguous United States, J. Clim. Appl. Meteorol., 23, 950-966, 1984.

Kumar, P. and Foufoula-Georgiou, E.: Wavelet Analysis in Geophysics: An Introduction, in: Wavelets in Geophysics, edited by: Foufoula-Georgiou, E. and Kumar, P., Academic Press, San Diego, p. 1-43, 1994.
Long, A. and Rippeteau, B.: Testing contemporaneity and averaging radiocarbon dates, American Antiquity, 39, 205-215, 1974.

Lund, S. P.: A comparison of Holocene paleomagnetic secular variation records from North America, J. Geophys. Res., 101, 80078024, 1996.

Madsen, D. B.: Two Holocene pollen records for the central Great Basin. Late Quaternary vegetation and climates of the American Southwest, edited by: Jacobs, B. F., Fall, P. L., and Davis, O. K., Am. Assoc, Stratigr. Palynol. Contrib., 16, 113-126, 1985.

Madsen D. B. and Currey, D. R.: Late Quaternary glacial and vegetation changes, Little Cottonwood Canyon area, Wasatch Mountains, Utah, Quat. Res., 12, 254-270, 1979.

Madsen, D. B., Rhode, D., Grayson, D. K., et al.: Late Quaternary environmental change in the Bonneville basin, western USA, Palaeo geography, Palaeoclimatology, Palaeoecology, 167, 243-271, 2001.

Madsen, D. B. and Simms, S. R.: The Fremont complex: a behavioral perspective, J. Word Prehist., 12, 255-336, 1998.

Murchison, S. B.: Fluctuation history of Great Salt Lake, Utah, during the last 13000 years, $\mathrm{PhD}$ thesis, University of Utah, Salt Lake City, 1989.

Murchison, S. B. and Mulvey, W. E.: Late Pleistocene and Holocene shoreline stratigraphy on Antelope Island, in: Geology of Antelope Island, edited by: King, J., Utah Geo. Surv. Misc., Publ. 00-1 pp. 77-83, 2000.

Qing, D. (Chief Ed.): Evolutions of Climate and environment in China, Science press, Beijing, 52-85, 2005.

Rhode, D. and Madsen, D. B.: Pine nut use in the early Holocene and beyond: the Danger Cave archaeodotanical record, J. Arch. Sci., 25, 1199-1210, 1998.

Ropelewski, C. F. and Halpert, M. S.: North American precipitation and temperature patterns associated with El Niño - Southern Oscillation (ENSO), Mon. Wea. Rev., 114, 2352-2362, 1986.

Seager, R., Kushnir, Y., Herweijer, C., Naik, N., and Velez, J.: Modeling of Tropical Forcing of Persistent Droughts and Pluvials over Western North America: 1856-2000, J. Climate, 18, 4065-4088, 2005.

Shin, S.-I., Sardeshmukh, P. D., and Webb, R. S.: Understanding the Mid-Holocene Climate, J. Climate, 19, 2801-2817, 2006.

Stine, S.: Past climate at Mono Lake, Nature, 345, 391-394, 1990.

Stine, S.: Extreme and persistent drought in California and Patagonia during mediaeval Time, Nature, 369, 546-549, 1994.

Storch, H. V. and Zwiers, F.: Statistical Analysis in Climate Research, Cambridge University Press, Cambridge, p. 116, 1999.

Wigand, P. E.: Diamond pond, Harney county, Oregon: Vegetation history and water table in the Eastern Oregon desert, Great Basin Naturalist, 1987, 47(3), 427-458, 1987.

Wigand, P. E. and Mehringer, P. J.: Pollen and seed analyses, in: The Archaeology of Hidden Cave, Nevada, edited by: Thomas, D. H., Anthrological Papers of the American Museum of Natural History, 61, 1985.

Yamamoto, R., Iwashima, T., Sanga, N. K., et al.: An analysis of climate jump, J. Meteorol. Jpn., 64, 273-281, 1986.

Ye De-Zheng and Chen Pan-Qing (Eds.): A pre-study of the global changes in China, Seismological Press, Beijing, 31-53, 1992.

Zhu Ke-Zhen: A primary study of climate changes in China for the past 5000 years, Sciences in China, 1979(2), 291-296, 1979. 